\title{
Obstetric anesthesia for the obese and morbidly obese patient: an ounce of prevention is worth more than a pound of treatment
}

Mieke A. Soens, David J. Birnbach, Jayanthie S. Ranasinghe and André van Zundert

Department of Anesthesiology, Perioperative Medicine and Pain Management, Jackson Memorial Hospital, Miami, FL 33136, USA

Background: The incidence of obesity has been dramatically increasing across the globe. Anesthesiologists, are increasingly faced with the care for these patients. Obesity in the pregnant woman is associated with a broad spectrum of problems, including dramatically increased risk for cesarean delivery, diabetes, hypertension and preeclampsia. A thorough understanding of the physiology, associated conditions and morbidity, available options for anesthesia and possible complications is therefore important for today's anesthesiologist.

Methods: This is a personal review in which different aspects of obesity in the pregnant woman, that are relevant to the anesthesiologist, are discussed. An overview of maternal and fetal morbidity and physiologic changes associated with pregnancy and obesity is provided and different options for labor analgesia, the anesthetic man- agement for cesarean delivery and potential post-partum complications are discussed in detail.

Results and conclusion: The anesthetic management of the morbidly obese parturient is associated with special hazards. The risk for difficult or failed intubation is exceedingly high. The early placement of an epidural or intrathecal catheter may overcome the need for general anesthesia, however, the high initial failure rate necessitates critical block assessment and catheter replacement when indicated.

Accepted for publication 24 July 2007

Key words: Obesity; anesthesia; analgesia; labor; cesarean. (C) 2008 The Authors

Journal compilation (C) 2008 The Acta Anaesthesiologica Scandinavica Foundation
$\mathrm{D}$ URING the last two decades, obesity has become a global epidemic, with more than 1 billion overweight adults worldwide. At least 300 million of them are clinically obese (1). This is a major contributor to the global burden of chronic disease and disability. The prevalence of obesity has reached alarming levels in the Western society and especially in the United States, although the problem is certainly not restricted to industrialized societies (2). In the United States, the problem is more pronounced in women than in men and certain ethnic groups are more affected than others $(2,3)$. The dramatically increasing rate of obesity in the general population also extends to women of reproductive age. A study looking at trends in prepregnancy obesity in nine states of the United States found an increase in pre-pregnancy obesity from $13 \%$ in $1993-1994$ to $22 \%$ in $2002-2003$ (4). Obesity increases the risk for cesarean delivery significantly and thus also the need for anesthesia (5). Anesthesiologists are thus increasingly faced with the care for morbidly obese patients.

\section{Maternal and fetal morbidity}

Obesity has become a ticking time bomb for life expectancy levels, with long-term health implications such as diabetes mellitus, hypertension, coronary artery disease, cerebrovascular disease, gallbladder and liver disease. Its responsibility as a triggering or favoring factor in many conditions in obstetrics is well recognized. Robinson et al. (6) showed that pre-pregnancy maternal obesity increases the risk of pregnancy-induced hypertension, venous thromboembolism, labor induction, cesarean delivery and wound infection. Obese and morbidly obese patients are also at increased risk 
for gestational diabetes. Large-for-gestational age fetuses and fetal macrosomia are more common in this population (5). Both obese and morbidly obese patients have a significantly increased risk for birth weight $>4500 \mathrm{~g}$ (5). Obese patients may have difficulty completing the second stage of labor secondary to soft tissue dystocia, with an increased risk for arrest of labor and cesarean delivery (5). The infant of the obese parturient is at increased risk for head trauma, shoulder dystocia, brachial plexus lesions and fractured clavicle (7). Maternal obesity also increases the risk of birth defects, especially neural tube defects, such as spina bifida (8). Additionally, ultrasonographic examination of the fetus is often more difficult in these patients.

\section{Pregnancy, obesity and physiology}

Both obesity and pregnancy are associated with significant physiologic changes and many of these changes have similar implications (Tables 1 and 2).

In early pregnancy, even before the uterus is large enough to affect respiratory function, women begin to have a sensation of dyspnea. This sensation likely occurs from the increased alveolar ventilation seen in pregnant patients, which is probably secondary to progesterone effects on the respiratory center in the brainstem $(9,10)$. By the fifth month of pregnancy, the mechanical effects of the growing uterus begin to produce a progressive decrease in expiratory reserve volume (ERV), residual volume (RV) and functional residual capacity
(FRC), which at term are about 15-20\% below those of the non-pregnant state (11).

Several studies (11-14) have shown that obesity in non-pregnant subjects is associated with a

Table 1

Respiratory changes in pregnancy, obesity and pregnancy and obesity combined (adapted from Saravanakumar et al. Obesity and obstetric anaesthesia. Anaesthesia 2006; 61: 36-48, with permission from Blackwell Publishing).

\begin{tabular}{|c|c|c|c|}
\hline Parameter & Pregnancy & Obesity & Combined \\
\hline Progesterone level & $\uparrow$ & $\leftrightarrow$ & $\uparrow$ \\
\hline Sensitivity to $\mathrm{CO}_{2}$ & $\uparrow$ & $\downarrow$ & $\uparrow$ \\
\hline Tidal volume & $\uparrow$ & $\downarrow$ & $\uparrow$ \\
\hline Respiratory rate & $\uparrow$ & $\leftrightarrow$ or $\uparrow$ & $\uparrow$ \\
\hline Minute volume & $\uparrow$ & $\downarrow$ or $\leftrightarrow$ & $\uparrow$ \\
\hline Inspiratory capacity & $\uparrow$ & $\downarrow$ & $\uparrow$ \\
\hline Inspiratory reserve volume & $\uparrow$ & $\downarrow$ & $\uparrow$ \\
\hline Expiratory reserve volume & $\downarrow$ & $\downarrow \downarrow$ & $\downarrow$ \\
\hline Residual volume & $\downarrow$ & $\downarrow$ or $\leftrightarrow$ & $\uparrow$ \\
\hline Functional residual capacity & $\downarrow \downarrow$ & $\downarrow \downarrow \downarrow$ & $\downarrow \downarrow$ \\
\hline Vital capacity & $\leftrightarrow$ & $\downarrow$ & $\downarrow$ \\
\hline $\mathrm{FEV}_{1}$ & $\leftrightarrow$ & $\downarrow$ or $\leftrightarrow$ & $\leftrightarrow$ \\
\hline $\mathrm{FEV}_{1} / \mathrm{VC}$ & $\leftrightarrow$ & $\leftrightarrow$ & $\leftrightarrow$ \\
\hline Total lung capacity & $\downarrow$ & $\downarrow \downarrow$ & $\downarrow$ \\
\hline Compliance & $\leftrightarrow$ & $\downarrow \downarrow$ & $\downarrow$ \\
\hline Work of breathing & $\uparrow$ & $\uparrow \uparrow$ & $\uparrow$ \\
\hline Resistance & $\downarrow$ & $\uparrow$ & $\downarrow$ \\
\hline VIQ mismatch & $\uparrow$ & $\uparrow$ & $\uparrow \uparrow$ \\
\hline $\mathrm{DL}_{\mathrm{CO}}$ & $\uparrow$ or $\leftrightarrow$ & $\leftrightarrow$ & $\leftrightarrow$ \\
\hline $\mathrm{PaO}_{2}$ & $\downarrow$ & $\downarrow \downarrow$ & $\downarrow$ \\
\hline $\mathrm{PaCO}_{2}$ & $\downarrow$ & $\uparrow$ & $\downarrow$ \\
\hline
\end{tabular}

$\uparrow$, increase; $\downarrow$, decrease; $\leftrightarrow$, no change (multiple arrows represent the degree of intensity).

$\mathrm{CO}_{2}$, carbon dioxide; $\mathrm{FEV}_{1}$, forced expiratory volume in $1 \mathrm{~s} ; \mathrm{VC}$, vital capacity; $V / Q$, ratio of ventilation to perfusion; $\mathrm{DL}_{\mathrm{co}}$, diffusion capacity of lung for carbon monoxide; $\mathrm{PaO}_{2}$, partial pressure of oxygen; $\mathrm{PaCO}_{2}$, partial presure of carbon dioxide.

Table 2

Cardiovascular changes in pregnancy, obesity and pregnancy and obesity combined (adapted from Saravanakumar et al. Obesity and obstetric anaesthesia. Anaesthesia 2006; 61: 36-48, with permission from Blackwell Publishing).

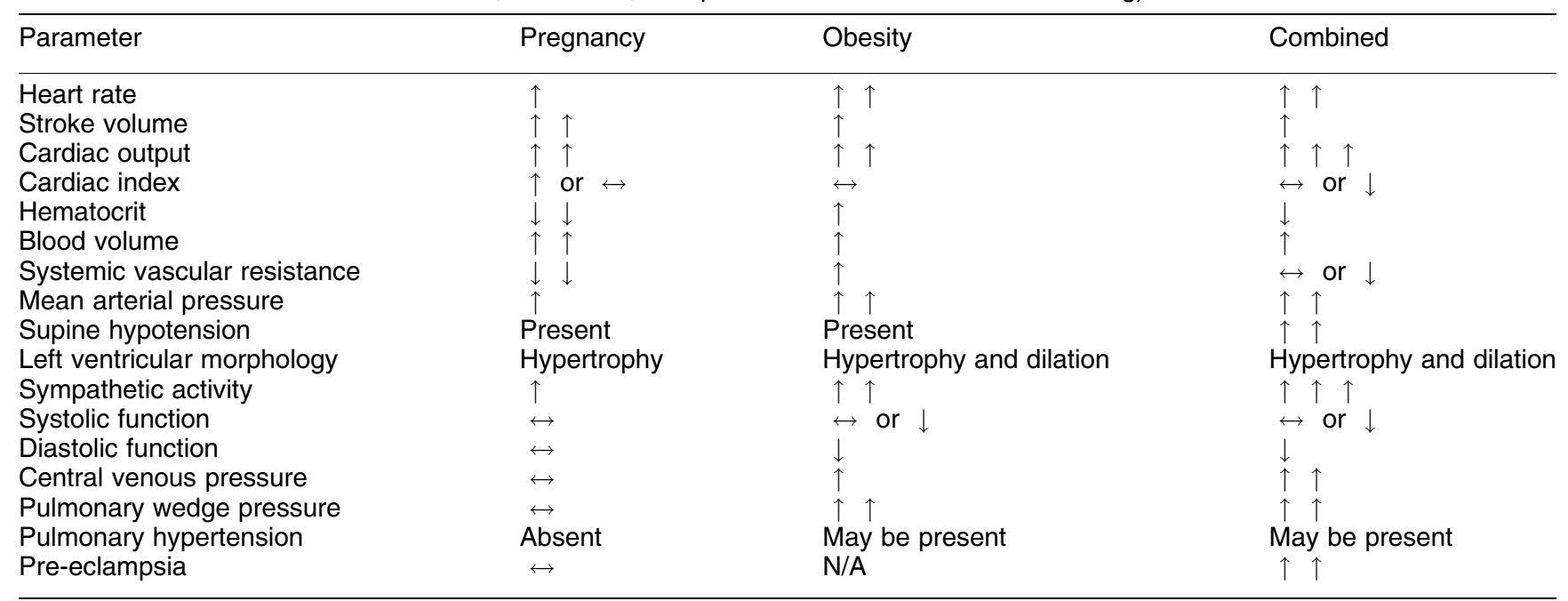

$\uparrow$, increase; $\downarrow$, decrease, $\leftrightarrow$, no change (multiple arrows represent the degree of intensity). N/A, not applicable. 
decrease in ERV, RV and FRC, most likely caused by the added weight and decreased compliance of the chest wall. A study by Eng et al. (11) showed, however, that obese pregnant women did not have a significant additional reduction in FRC, as is the case in normal-weight pregnant patients. According to these authors, it is possible that these findings can be partially explained by the fact that the study was performed with the patients in the sitting position. The supine and especially the Trendelenburg position worsen lung volumes significantly. Another possible explanation is that the relaxing effect of progesterone on smooth muscle decreases airway resistance, thus reducing some of the negative effects of obesity on the respiratory system $(10,15)$. Arterial blood gas analysis demonstrates hypoxemia in the obese parturient much more frequently than in the non-obese, which suggests a greater degree of venoarterial shunting (11). This is especially true when the FRC is further reduced by the induction of general anesthesia or when the patient assumes the supine or the Trendelenburg position (16). The FRC may fall below the closing capacity, leading to airway closure, especially in the dependent lung regions and, thereby, causing increased venoarterial shunting (16). The work of breathing is increased in obese parturients due to chest wall weight and they typically show a rapid and shallow breathing pattern (17). This leads in turn to a higher ventilatory requirement and oxygen cost of breathing $(10,18)$. Dempsey et al. (17) showed that excess body weight increases oxygen consumption and $\mathrm{CO}_{2}$ production in a linear fashion. These physiologic changes make the obese parturient particularly prone to rapid desaturation, stressing the importance of adequate denitrogenation ('pre-oxygenation') before induction of general anesthesia.

In non-obese pregnant women, physiologic changes during pregnancy are thought to protect from obstructive sleep apnea, due to high circulating levels of progesterone, which is a ventilatory stimulant (19). However, obesity increases the risk for obstructive sleep apnea significantly and this syndrome is not uncommon in the obese pregnant woman. Obstructive sleep apnea has been associated with increased systemic hypertension and also possibly pulmonary hypertension (20). Additionally, these patients are at an increased risk for coronary artery disease, stroke and cardiac arrhythmias (20). Maternal oxygen desaturation, occurring as a result of apnea, may result in fetal hypoxia and poor fetal growth (21). Obstructive sleep apnea usually presents clinically as a combination of loud snoring and excessive daytime sleepiness. Because daytime fatigue is very common in pregnancy, this disease is often not identified. Recognizing obstructive sleep apnea early in gestation will help dictate treatment options and may prevent adverse maternal fetal outcomes, especially as relates to post-cesarean pain management. Continuous positive airway pressure (CPAP) is a safe treatment with minimal adverse effects and may improve perinatal outcomes (21).

Both obesity and pregnancy have profound effects on the maternal cardiovascular system. Pregnancy is associated with a significant increase in cardiac output, becoming detectable by the third week of pregnancy, with a 35-40\% increase by the end of the first trimester. Cardiac output continues to rise throughout the second trimester until it reaches a level that is approximately $50 \%$ greater than that in the non-pregnant state. For the remainder of the pregnancy, cardiac output remains relatively stable around that level. During labor, cardiac output increases further by approximately $10 \%$ in the early first stage, $25 \%$ in the late first stage and $40 \%$ in the second stage. Uterine contractions are associated with an additional 10-15\% increase and in the immediate post-partum period the cardiac output peaks at as much as $75 \%$ above pre-delivery values (22). Obesity increases cardiac output even further because any extra amount of fat deposited in the body demands its share of cardiac output. Every $100 \mathrm{~g}$ of fat increases the cardiac output by $30-50 \mathrm{ml} / \mathrm{min}$ (23). Blood volume is increased in pregnancy and even more when pregnancy is complicated by obesity. In non-obese women, pregnancy is associated with a significant reduction in afterload (23). In obese pregnant patients, however, afterload reduction may be impaired due to increased peripheral resistance and greater conduit artery stiffness (24). Additionally, obesity is associated with a higher prevalence of hypertension, diabetes mellitus, hyperlipidemia and poor cardiac function and it is one of the leading risk factors for coronary artery disease and cerebrovascular accidents (25). During pregnancy, these adverse effects of obesity are exacerbated partially due to the secretion of human placental lactogen, human chorionic gonadotropin and steroid hormones, which increase the resistance of target tissue to insulin. Estrogen also accelerates the insulin secretion from pancreatic $\beta$ cells. These changes during pregnancy lead to 
hyperinsulinemia and fat deposition, very similar to the pathophysiological status of obesity (25). The dramatically increased cardiac demands in combination with the potentially decreased functional reserves of the heart in obese patients places the obese parturient at particular risk during the peripartum period. In addition, obesity has been mentioned as a risk factor for peripartum cardiomyopathy, a potentially lethal disease (26). There have been several reports of cardiac arrest in both pregnant and non-pregnant morbidly obese surgical patients $(27,28)$. Sudden circulatory changes associated with positional change may have accounted for the sudden death in some of these patients (27). During the second half of pregnancy, aortocaval compression by the uterus in the supine position can severely reduce cardiac output and placental perfusion. This problem is greatly exacerbated in the obese parturient, when the large fat panniculus may further compress the great vessels (29). Drenick and Fisler (30) reported that morbidly obese patients are more prone to develop fatal arrhythmias. Even minor or borderline $Q-T$ interval prolongation can result in sudden cardiac death in these patients. Therefore, medications known to prolong the $Q-T$ interval, such as erythromycin, droperidol, granisetron, nicardipine, methadone and others, are best avoided in these patients.

Both obesity and pregnancy have been associated with an increased risk for aspiration and Mendelson's syndrome $(31,32)$. Whether the combination of pregnancy and obesity further increases the risk for pulmonary aspiration of gastric contents has not been clearly demonstrated, but seems likely (33). Roberts and Shirley (34) found that weight was a significant factor in gastric content volume during labor. However, this was not found to be the case in patients scheduled for elective cesarean delivery. On the other hand, Vaughan et al. (35) found that obese, non-pregnant patients scheduled for elective surgery had both a larger volume and a lower gastric $\mathrm{pH}$ than non-obese patients. In addition, obese patients have a higher incidence of hiatus hernia and elevated intra-gastric pressures, which further increases the risk for pulmonary aspiration of gastric contents (29). Obesity is one of the major risk factors for diabetes, which in turn can cause delayed gastric emptying, increasing the risk for aspiration. Also, it is well known that obesity pre-disposes to difficult or failed intubation, both of which are associated with a higher incidence of aspiration.

\section{Anesthetic management of the obese parturient}

\section{Analgesia for labor}

Obesity is associated with an increased incidence of fetal macrosomia, which is a known risk factor for more painful contractions and complicated labor (36). Melzack et al. (37) studied the influence of physical variables on the severity of labor pain using the McGill pain questionnaire, and reported a positive correlation of BMI with the severity of labor pain. These findings were not confirmed, however, in a later study conducted by Ranta et al. (38)

Although regional analgesia offers many advantages in the obstetric patient, these techniques can be very challenging in the obese parturient. This review will discuss several options, but no anesthetic technique is without difficulty in the obese parturient.

Hawkins and colleagues $(39,40)$ reported that general anesthesia for cesarean delivery was associated with a much higher risk of maternal mortality as compared with regional anesthesia. The 1991 ASA Closed Claim Study (41) found that maternal death claims were related pre-dominantly to the use of general anesthesia, specifically secondary to the inability to establish or maintain a patent airway. Obesity was found to be a major risk factor for maternal mortality in several studies $(42,43)$, with failed intubation and aspiration representing the cause of death in the majority of cases. The incidence of failed intubation in the morbidly obese parturient has been reported to be as high as $33 \%$ (33). One way to avoid these complications is to place a functioning epidural or spinal catheter in early labor in every morbidly obese parturient, provided that no contraindication to do so exists. The catheter can then be used in case of emergent cesarean section to build a solid level of anesthesia in a short period of time, hence avoiding the need for general anesthesia. The American College of Obstetricians and Gynecologists (ACOG) has recognized the importance of identifying women at risk for difficult intubation in Committee Opinion Number 104 (44). They made the following statement: 'For those patients at risk, consideration should be given to the planned placement in early labor of an epidural catheter, with confirmation that the catheter is functional.' Gaiser et al. (45) assessed the ability of obstetricians to recognize parturients at risk for difficult intubation. They found that instruction in airway examination did 
not affect obstetrician's ability to predict difficult airways, but it did, however, increase the use of early epidural analgesia.

\section{Continuous lumbar epidural analgesia}

Epidural placement is often difficult in morbidly obese patients, because anatomical landmarks are obscured. Jordan et al. (46) noted that $74.4 \%$ of these patients needed more than one attempt and $14 \%$ needed more than three attempts for successful epidural needle placement. Additionally, the incidence of accidental dural puncture may be as high as $4 \%$ in morbidly obese parturients, compared with $0.5-2.5 \%$ in non-obese patients $(47,48)$. The identification of the midline can be particularly challenging in the obese parturient. Although some authors prefer catheter insertion with the patient in the lateral recumbent head-down position, because this may decrease the incidence of intravascular placement by reducing venous congestion in the epidural veins (49), we prefer the sitting position because the line joining the occiput or prominence of C-7 and the gluteal cleft can be used to approximate the position of the midline. In addition, Hamza et al. (50) found that the distance from the skin to the epidural space was significantly shorter when the epidural was performed with the patient in the sitting position compared with the lateral decubitus position. These authors also reported that weight and BMI were positively correlated with the distance to the epidural space (Fig. 1). These findings are supported by a study (51) in which computed tomography was used to measure the depth of the epidural space in non-pregnant patients and found a significant correlation between BMI and distance from the skin to the epidural space. However, Watts (52) showed that in obese patients, $\mathrm{BMI}$ is a poor predictor of distance to the epidural space compared with the non-obese group. In obese individuals, the excess body mass can be distributed disproportionately to areas other than the lower lumbar region. Therefore, while one expects the distance to be greater than anticipated, the epidural space in an obese patient may actually be closer to the skin than expected for their weight. While longer needles are occasionally necessary, the majority of studies report that only a few patients have an epidural space deeper than $8 \mathrm{~cm}$ $(50,52)$. Therefore, it seems prudent to use a standard epidural needle for the first attempt, instead of one of the longer epidural needles available. Patient guidance, in which the parturient

\section{Distance From Skin to Epidural Space According to $\mathrm{BMI}$ and Position}

Source: Hamza et al., J. Clin. Anesth., vol. 7, February 1995

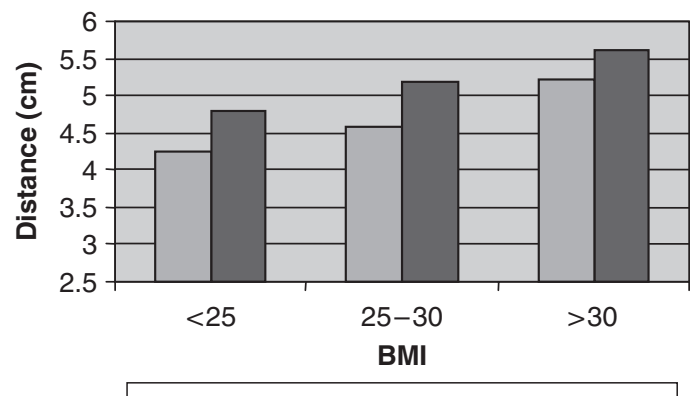

$\square$ Sitting Position $\quad \square$ Left Lateral Decubitus

Fig. 1. Distance from the skin to the epidural space according to BMI and position.

assists the anesthesiologist verbally by indicating whether she feels the needle more on the left or the right side of the spine, may prove to be a valuable tool when trying to identify the midline in these morbidly obese patients. In a pilot study by Wills et al. (53), the authors investigated the ability of volunteers to identify the midline of their own backs, using light touch or proprioception. They found that sensation to light touch was the most accurate, with $90 \%$ of the volunteers able to identify the midline to within $6.5 \mathrm{~mm}$. Another method, described by Maitra et al. (54), uses an $8.5 \mathrm{~cm}$, 26-gauge needle to probe for a posterior process of a lumbar vertebra. When the lumbar process is located, it can be used as a landmark for epidural needle insertion. In case difficult epidural placement is encountered, ultrasound imaging should be considered (55). Grau et al. (56) suggested that the quality of images obtained with a paramedian longitudinal approach is superior compared with images obtained with transverse and median longitudinal approaches (probably due to a wider 'acoustic window'). However, it is our experience that the transverse approach is often easier to perform. Also, for the placement of neuraxial blocks in obstetrics, a midline approach for epidural needle insertion is often preferred, making the transverse approach a more logical choice. Images obtained with a transverse approach permit identification of the midline, through visualization of the spinous processes. Each spinal process accounts for one shadow and the adjacent intervertebral space for one acoustic window. However, it is our experience that it is often difficult in obese patients to identify the shadow of the spinal process. Instead, the symmetry of the paraspinous muscles can be used, as illustrated in Fig. 2. Also 

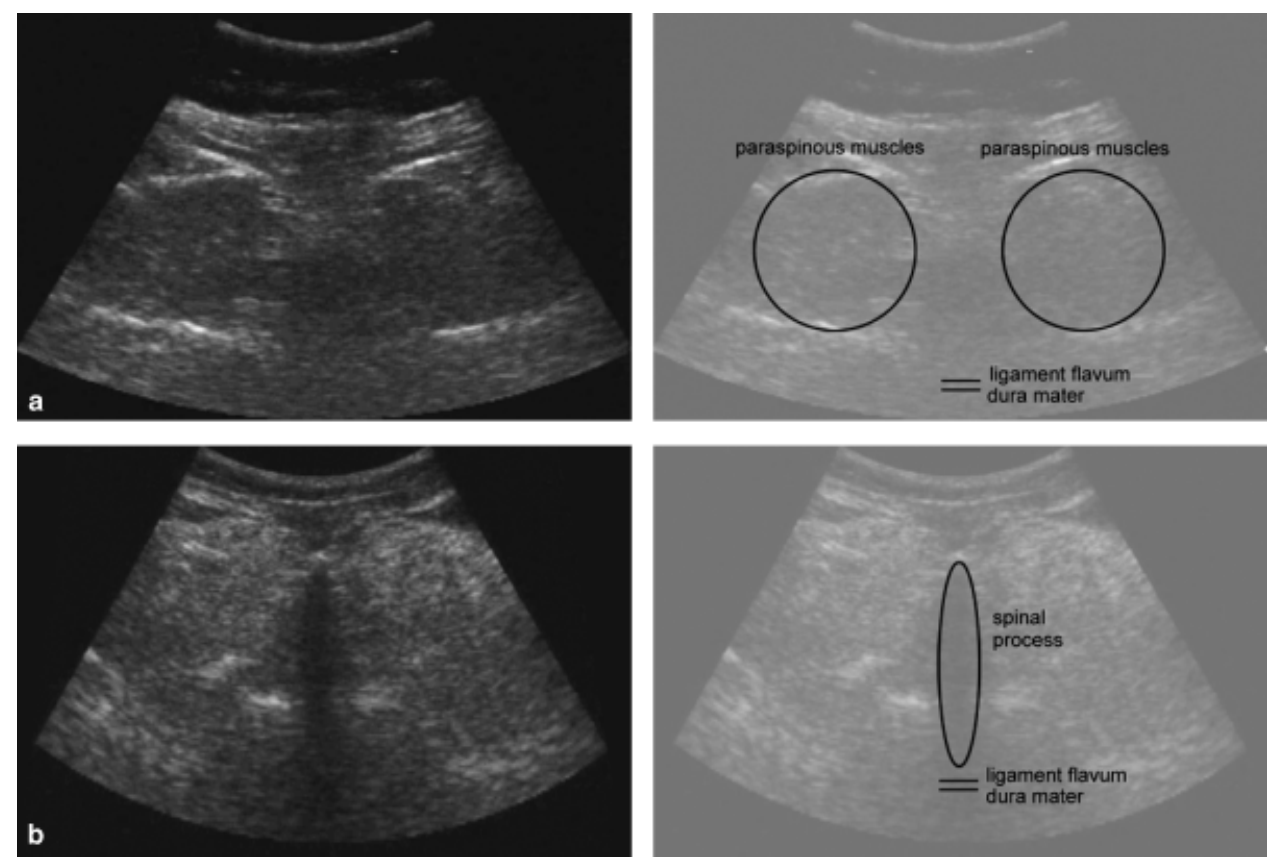

Fig. 2. In obese patients, it is often difficult to identify the shadow of the spinal process. Instead, the symmetry of the paraspinous muscles can be used to localize midline.

the depth of the epidural space is predictable from ultrasound depth measurements, through visualization of the ligamentum flavum $(55,57)$.

Following correct epidural catheter placement, the risk of epidural catheter dislodgement is increased in the obese patient. Sliding of the skin over subcutaneous tissue has been proposed as an important factor in epidural catheter migration (58), Iwama and Katayama (59) noticed $3 \mathrm{~cm}$ skin movement in some patients. To avoid the tendency of epidural catheters to 'walk,' they routinely place catheters $7 \mathrm{~cm}$ in the epidural space. Hamilton et al. (60) demonstrated that epidural catheters not fixed at the skin could move $1-2.5 \mathrm{~cm}$ inward when the parturient's posture is changed from the sitting to the lateral recumbent position, with the greatest change seen in patients with a BMI $>30$. Therefore, it may be prudent to place the parturient in the lateral position before securing the catheter to the skin $(54,60)$. Suturing the epidural catheter to the skin, using an adhesive dressing wrapped around the catheter at the point of insertion, with a single stitch passed through the dressing and sutured to the skin adjacent to the catheter entry site, has been recommended (61). However, this does not prevent the movement of the skin relative to the epidural space and we do not suture our catheters.

\section{Combined spinal epidural (CSE) anesthesia}

CSE has become a well-established alternative to epidural analgesia to provide labor analgesia.
Compared with classical epidural, CSE provides a faster onset of effective pain relief, and increases patient satisfaction. However, the effect of intrathecal opioids on the incidence of uterine hyperactivity and fetal heart rate abnormalities remains controversial. Another potential drawback of CSE is that the location of the epidural catheter is initially uncertain. In an emergency, this 'unproven' catheter may fail to provide adequate anesthesia. On the other hand, several studies (62-65) have shown that catheters inserted as part of a CSE technique produce anesthesia/analgesia more reliably than those inserted via a standard epidural technique. The appearance of CSF in the hub of the spinal needle indirectly confirms correct epidural needle placement and thus increases the likelihood of a proper working catheter. Nevertheless, the failure rate of epidural catheters in the general obstetric population varies between $8 \%$ and $13 \%$ $(65,66)$, with the major causes of failure being no analgesia/anesthesia and unilateral block. Hood et al. (48) found that this failure is even more likely when the parturient is morbidly obese. They reported an initial epidural catheter failure rate of $42 \%$ in these patients, compared with $6 \%$ in control patients. The need for significantly more local anesthetic than usual to maintain analgesia should ring an alarm bell. The epidural may not be functioning properly and consideration should be given to replacing it (65). This is even more so, as significantly lower epidural analgesic requirements 
have been reported in obese parturients when compared with normal patients, probably secondary to a reduced volume in their epidural and subarachnoid space due to increased abdominal pressures $(67,68)$.

\section{Continuous spinal analgesia}

Because of this relatively high failure rate of epidural catheters in the obese population and the importance of having a 'working catheter' in case an emergency develops, at our institution, we often prefer intentional continuous spinal analgesia/ anesthesia in these patients. In addition, when accidental dural puncture occurs during intended epidural placement, continuous spinal analgesia/ anesthesia should be considered. This technique provides considerable predictability and reliability, allowing tight control of the anesthetic level and duration of the block. The spinal catheter should be clearly labeled and all personnel should be made aware of the nature of the catheter to prevent inadvertent injection of medication intended for epidural use. One possible complication of the continuous spinal technique is the development of post-dural puncture headache (PDPH), occurring in $30-70 \%$ of obstetric patients following accidental dural puncture with a 17-gauge Tuohy needle (69). However, Faure et al. (47) showed that the risk of PDPH is significantly decreased in morbidly obese parturients. The reason for this may be that the large abdominal panniculus functions as the equivalent of an abdominal binder, elevating intra-abdominal pressures and reducing the degree of spinal fluid leakage through the dural puncture site (47). Although controversial, the incidence of PDPH seems to be decreased even more when continuous spinal anesthesia (CSA) is used. In non-pregnant, non-obese patients, it has been shown that CSA decreases the incidence of spinal headache to $<1 \%$ (70). Norris and Leighton (71) failed to show a reduced incidence of headaches in parturients after leaving the intrathecal catheters in situ for at least $2 \mathrm{~h}$. Cohen et al. (72), however, found that after prolonged ( $>24 \mathrm{~h}$ ) spinal catheterization with the use of post-operative analgesia, none of their patients suffered from PDPH. Denny et al. (70) speculated that the catheter initially acts as a barrier to CSF leakage and later causes an inflammatory fibrous reaction at the site of catheterization in the dura. Norris et al. (73) showed that puncturing the dura with the bevel of the needle parallel to the longitudinal axis of the back de- creases the incidence of PDPH significantly. They have suggested that after obtaining clear CSF, the needle should be rotated gently to orient the bevel cephalad and a spinal catheter can be threaded. Most authors $(70,71)$ advocate leaving the catheter $2-4 \mathrm{~cm}$ in the subarachnoid space.

\section{Anesthesia for cesarean delivery in the obese and morbidly obese patient}

Obesity significantly increases the incidence of cesarean delivery. Weiss et al. (5) found for nulliparous patients a cesarean delivery rate of $20.7 \%$ in the control group compared with $33.8 \%$ in the obese and $47.4 \%$ in the morbidly obese group. In addition, obesity is associated with an increase in maternal mortality, morbidity and operative complications such as excessive blood loss, an increased operative time and increased incidence of post-operative wound infection and endometritis $(5,74)$. Good communication between anesthesiologists, obstetricians and nursing staff is mandatory on every labor and delivery ward, but even more so when dealing with the morbidly obese parturient. These patients can certainly benefit from antepartum anesthesiology consultation and multidisciplinary meetings with obstetricians, anesthesiologists and nursing staff in which key points can be discussed beforehand, such as the availability of a suitable bed and operating table, surgical technique and panniculus retraction, thromboembolism prophylaxis, type and cross match, post-operative care and overnight monitoring in an intensive care unit and possible comorbidities and their consequences. An appropriately sized operating table is imperative. The use of two operating tables (side by side) has been described (75). The problem with this technique is that it is impossible to raise, lower or change the position of the tables in a completely synchronous manner. Another possibility is to use one set of armboards, placed parallel to the operating table to extend the width of the table, while an extra set of armboards can be used to position the arms of the patient. When dealing with the morbidly obese parturient, the anesthesiologist should evaluate the patient's ability to lie supine, especially when considering regional anesthesia, because cephalad retraction of a large panniculus can further compromise respiratory function. If the patient suffers from sleep apnea, and was using CPAP pre-operatively, this modality should be available for intra-operative 
and post-operative use also. The ASA Practice Guidelines for the Perioperative Management of Patients with Obstructive Sleep Apnea recommend the pre-operative initiation of CPAP in patients with severe obstructive sleep apnea, as this may improve their pre-operative condition (76). Nasal CPAP (n-CPAP) at $10-15 \mathrm{~cm}$ of water has been used successfully for purpose (77-79). Although controversial (80), many consider obesity as an important risk factor for venous thromboembolism $(81,82)$ and prophylaxis should be considered. Another problem that the anesthesiologist often encounters when dealing with morbidly obese patients is difficulty with non-invasive blood pressure monitoring. Unless the length of the cuff exceeds the circumference of the arm by $20 \%$, systolic and diastolic blood pressure measurements may overestimate true maternal blood pressure. In some cases, the use of a radial intra-arterial catheter may be preferable, especially in patients with comorbidities such as chronic hypertension and preeclampsia. An intra-arterial catheter also offers the advantage of having the opportunity to perform repeated blood gas sampling, if indicated.

\section{Regional anesthesia}

Many anesthesiologists use decreased amounts of neuraxial local anesthetic in obese patients out of fear for an unpredictable and exaggerated spread with possible high spinal block. These concerns are supported by the findings of Hodgkinson and Husain (83), who described an increased cephalad spread of local anesthetics in obese patients. Hogan et al. (67) found a lower average CSF volume in subjects with a high BMI, which could explain the decreased local anesthetic dose requirements in obese patients due to decreased anesthetic dilution. Because similar changes were noticed with external abdominal compression and abdominal pressure increases linearly with increased body weight (84), increased abdominal pressure is probably the cause. Others (85) have also attributed the decrease in CSF volume to compression of the dural sac due to engorgement of the epidural venous plexus and increased epidural space pressure, secondary to compression of the inferior vena cava with redistribution of the venous return from the lower limbs and pelvis. Hogan et al. (67), however, postulated that the mechanism by which increased abdominal pressure decreases the CSF volume is probably inward movement of soft tissue (mostly fat) in the intervertebral foramen, which displaces CSF.
This hypothesis is based on their findings that the greatest change in CSF volume during abdominal compression was found at sites in which intervertebral foramina were present.

Spinal anesthesia is widely used for elective cesarean delivery. However, in the morbidly obese parturient, this technique may involve additional risks. First, as discussed above, obesity may result in an unpredictable, exaggerated spread of local anesthetics and may therefore increase the risk of a high spinal block. As a result, it may be difficult to determine the optimal amount of local anesthetic required to produce a sufficient level of anesthesia for cesarean delivery. Moreover, a single-dose spinal injection produces only a finite period of anesthesia, and surgery in these patients may be prolonged, requiring additional anesthesia (86). Epidural anesthesia via an epidural catheter could overcome this problem; however, epidural block may be inadequate in more than $25 \%$ of these patients, mainly because of difficulty in blocking the sacral roots, resulting in visceral pain upon stimulation of the bladder (87). A CSE technique for cesarean delivery combines the quality of a spinal block with the flexibility of an epidural catheter. In addition, it has been shown that lower doses of local anesthetics are needed using a CSE technique compared with a single-shot spinal technique, which can possibly be explained by the fact that epidural insertion causes a change in epidural pressure (from subatmospheric to atmospheric), with compression of the lumbar thecal sac. This could possibly enhance the extent and duration of the spinal component when using a CSE technique (88). This and the flexibility of epidural supplementation of anesthesia afforded by CSE may justify using significant lower doses of local anesthetics, which may reduce the risk of a total spinal block and also possibly reduce side effects, such as hypotension (89). On the other hand, as discussed previously, the epidural catheter remains initially 'unproven' and may fail to provide adequate anesthesia when the spinal block wears off. CSA can overcome these disadvantages. It produces reliable anesthesia and the catheter allows incremental dosing and precise extension of the block when greater duration is necessary. Achievement of a surgical anesthetic level can occur within minutes in emergency situations, with small increments of a local anesthetic.

Regardless of the regional technique used, a thorough assessment of the block before surgical incision is even more important in the morbidly 
obese parturient than in the non-obese one, as inadequate block and the need for conversion to general anesthesia during surgery may result in catastrophic sequelae in these patients.

\section{General anesthesia}

Prevention of acid aspiration is important in every parturient, but even more so in the obese patient. At our institution, it is standard practice to administer $30 \mathrm{ml}$ of a non-particulate antacid $(0.3 \mathrm{M}$ sodium citrate or its equivalent) before the initiation of any anesthetic being administered to a pregnant patient. This agent will rapidly decrease the acidity of gastric contents and help ameliorate the consequences of aspiration. The optimal time for administration of a non-particulate antacid is approximately a half an hour before the procedure $(34,90)$. For elective cesarean delivery, oral administration of an $\mathrm{H}_{2}$ antagonist, such as ranitidine, or a proton pump inhibitor, such as omeprazole, the evening before and again $60-90 \mathrm{~min}$ before the induction of anesthesia, may further reduce gastric acidity and volume (91) However, the addition of a prokinetic agent, such as metoclopramide, may be necessary to maximize the effect $(92,93)$. Metoclopramide can be particularly useful for those parturients who have ingested a large meal shortly before arrival and in the diabetic patient, whose disease results in delayed gastric emptying. Obese patients have a higher incidence of both of these conditions (34).

The incidence of difficult airway among obese parturients is much higher than among non-obese patients $(42,94)$. Especially, patients with a large neck circumference and/or a high Mallampati score may be difficult to intubate (95). In addition, there is not only an increased risk of failed intubation but also increased difficulty in maintaining adequate mask ventilation (94). The obese parturient is particularly prone to rapid desaturation. Preoxygenation (denitrogenation) before induction of general anesthesia is crucial in these patients. Three different techniques have been described in the literature. The most common method is $3-5 \mathrm{~min}$ of $100 \% \mathrm{O}_{2}$ breathing. Hamilton and Eastwood (96) demonstrated that denitrogenation is $95 \%$ complete within 2-3 min after breathing at a normal tidal volume from a circle anesthesia system with an oxygen flow of $5 \mathrm{l} / \mathrm{min}$. However, in obstetric emergencies, there may not be adequate time for pre-oxygenation using this technique. Gold et al. (97) showed that four maximally deep inspirations of $100 \% \mathrm{O}_{2}$ within $30 \mathrm{~s}$ are as effective as $5 \mathrm{~min}$ of inhalation of $100 \% \mathrm{O}_{2}$ in increasing $\mathrm{PaO}_{2}$ in the non-pregnant, non-obese patient. Similar results were later obtained by Norris and Dewan (98) for the pregnant patient. More recently, Baraka et al. (99) showed that pre-oxygenation achieved by eight deep breaths within $60 \mathrm{~s}$ at an oxygen flow of $101 / \mathrm{min}$ not only resulted in a higher $\mathrm{PaO}_{2}$ but also in a slower hemoglobin desaturation compared with the four deep breaths technique. A study comparing these three different pre-oxygenation techniques in pregnant women showed that the eight deep breaths and $3 \mathrm{~min}$ of tidal volume breathing with an $\mathrm{FiO}_{2}$ of $100 \%$ performed better than four deep breaths. In addition, the desired level of denitrogenation was obtained more rapidly in the eight deep breaths technique compared with the $3 \mathrm{~min}$ of tidal volume breathing, making the eight deep breaths method more suitable for obstetric emergencies (100). Position may also be important. Pre-oxygenation has been shown to be more effective in the sitting or the $25^{\circ}$ head-up position than in the supine position in severely obese patients $(101,102)$.

The increased risk for failed intubation, the possible difficult mask ventilation, and the need for rapid sequence induction with cricoid pressure
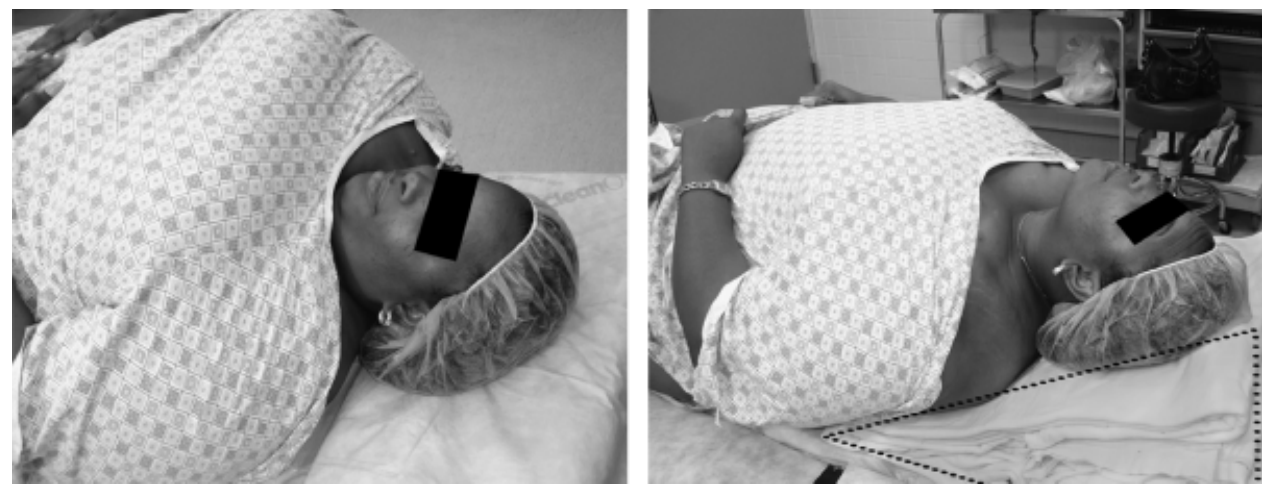

Fig.3. Demonstrates the change in airway when ramp is utilized. 
underscore the need for an additional pair of experienced hands during the administration of general anesthesia in the obese patient (33). In elective cases, awake fiberoptic intubation should be considered. However, this is not an ideal technique for emergencies. Although the use of LMA in obstetrics cannot prevent gastric content aspiration, it can be life saving in case of failed intubation. In addition, a study of Brain et al. (103) noted an upward trend of seal pressure with increasing BMI, an interesting finding that warrants further investigation.

Collins et al. (104) investigated the effect of the position of the patient on the view obtained during laryngoscopy in 60 morbidly obese patients. They found that the 'ramped' position, accomplished by arranging blankets underneath the patient's upper body and head until horizontal alignment is achieved between the external auditory meatus and the sternal notch, clearly improves the laryngeal view when compared with the standard 'sniff' position (Fig. 3).

Obesity alters the distribution of and response to anesthetic drugs. Because of increased blood volume, cardiac output and muscle mass, a higher initial induction dose of thiopental may be necessary in the obese patient. The elimination half-life and thus the duration of action is prolonged however, and the administration of a larger dose may be associated with delayed arousal in the event of failed intubation $(33,105)$. For propofol there is no difference in the initial distribution volume between obese and non-obese patients and it has been suggested that the induction dose should be based on lean body weight (105). Succinylcholine is still the muscle relaxant of choice for intubation in the obstetric patient. The duration of action of succinylcholine is determined by the level of pseudocholinesterase activity and the volume of extracellular fluid $(106,107)$. Both of these factors are increased in obesity. Therefore, it has been suggested (107) that succinylcholine should be administered on the basis of total rather than lean body weight in non-pregnant patients. However, pregnancy reduces pseudocholinesterase activity. Hence, a dose of $1.0-1.5 \mathrm{mg} / \mathrm{kg}$ (up to a maximum of $200 \mathrm{mg}$ ) succinylcholine is reasonable (33). After delivery, most anesthesiologists will either dramatically decrease or discontinue the administration of volatile-halogenated agents to allow for optimal uterine involution, and increase the concentration of nitrous oxide. However, in the obese patient it may not be possible to give as high a concentration of nitrous oxide as would be given to a non-obese patient, because these patients often require a higher inspired concentration of oxygen. Desflurane has been shown to be a safe supplement to the nitrous oxide-oxygen mixture for cesarean delivery and has been associated with faster recovery times and higher oxygen saturations on entry in the recovery room when compared with sevoflurane in morbidly obese patients $(108,109)$. Small doses of opioids as well as midazolam are usually administered to reduce the risk of intra-operative maternal awareness. In obesity, higher loading doses of midazolam are needed to reach adequate serum concentrations because of the highly lipophilic nature of the drug and the larger volume of distribution. Prolonged sedation should then be expected (105). Emptying of the stomach with an orogastric tube before extubation may help prevent gastric content aspiration. Extubation should only be attempted in fully awake patients with adequate reversal of neuromuscular blockade and preferably in the semi-upright position, as this minimizes compression of the diaphragm by abdominal contents $(76,110)$.

\section{Post-partum morbidity}

Many post-partum complications, such as hemorrhage, endometritis, wound infection, deep venous thrombosis (DVT), pulmonary embolism (PE), respiratory depression and hypoxemia occur more frequently in morbidly obese women (47). Naef et al. (111) found that maternal obesity is associated with a significant increase in the risk for hemorrhage during or following abdominal delivery. Type and cross match should therefore be considered beforehand in these women. Several studies $(74,112,113)$ have noted an increased risk of endometritis and wound infection after cesarean delivery in the obese patient and prophylactic antibiotics should be administered after clamping the umbilical cord, because this has been shown to reduce the incidence of infectious morbidity after cesarean section (114). Morbidly obese patients are also at an increased risk for serious, potentially lifethreatening complications such as hypoxemia, DVT, PE and post-partum cardiomyopathy (47). Eichenberger et al. (115) found that general anesthesia in morbidly obese patients generated much more atelectasis than in non-obese patients. Moreover, atelectasis remained unchanged for at least $24 \mathrm{~h}$ in morbidly obese patients, whereas atelectasis 
disappeared in the non-obese. Similarly, the decrease in respiratory function after spinal anesthesia has been shown to be significantly greater in the obese parturient compared with the non-obese one, with a significantly slower recovery (116). Semirecumbent position, early mobilization and adequate pain control can certainly contribute to the early resolution of atelectasis and a faster recovery of pulmonary function $(116,117)$. Both systemic and neuraxial opioids are used for post-cesarean delivery analgesia; however, neuraxial opioids are more effective than intravenous opioids (118). In addition, neuraxial opioids, when compared with systemic opioids, have been shown to decrease the incidence of atelectasis and reduce the incidence of pulmonary complications (119). However, opioids should be used with caution because of the increased risk for respiratory depression especially in patients with sleep apnea. Vigilant nursing monitoring for signs of respiratory depression, on an hourly basis during the first $24 \mathrm{~h}$ and then every $2 \mathrm{~h}$ for the second $24 \mathrm{~h}$ post-operatively has been recommended (120). Because of the increased risk for venous thromboembolism in obese patients, both mechanical and pharmacological measures for thromboprophylaxis should be undertaken. Optimal dosing of low molecular-weight heparin (LMWH) therapy has not yet been established for morbidly obese patients. It has been suggested that LMWH dosing should be based on actual body weight (121).

The anticoagulation status of the patient becomes particularly important for the anesthesiologist when the patient has a spinal or an epidural catheter. According to European guidelines (when a single daily dosing of LMWH's is used), catheters can be removed 10-12 h after the last dose of LMWH and $4 \mathrm{~h}$ before the next dose. In the United States, physicians commonly use twice-daily dosing of LMWH and according to the American Society of Regional Anesthesia and Pain Medicine guidelines, neuraxial catheters should be removed $2 \mathrm{~h}$ before the first dose and the first dose should be $24 \mathrm{~h}$ after surgery. The administration of a small dose (5000 U) of SC heparin has not been considered to be a contraindication for neuraxial techniques (122).

\section{Conclusion}

Obesity rates are soaring in most parts of the world and health care providers should be prepared to deal with this rapidly growing problem. The anes- thetic management of the morbidly obese parturient is associated with special hazards. The risk for difficult or failed intubation is exceedingly high. Early placement of an epidural catheter may overcome the need for general anesthesia; however, the high initial failure rate necessitates critical block assessment and catheter replacement when indicated. A continuous spinal technique is an attractive alternative for several reasons: it provides considerable predictability and reliability, allows tight control of the anesthetic level and duration of the block and achievement of a surgical anesthetic level can occur within minutes in emergency situations.

\section{References}

1. Haslam DW, James WP. Obesity. Lancet 2005; 366: 1197-209.

2. Hossain P, Kawar B, El Nahas M. Obesity and diabetes in the developing world - A growing challenge. $N$ Engl J Med 2007; 356: 213-5.

3. Canoy D, Buchan I. Challenges in obesity epidemiology. Obes Rev 2007; 8 (Suppl. 1): 1-11.

4. Kim SY, Dietz PM, England L et al. Trends in pre-pregnancy obesity in nine states, 1993-2003. Obesity (Silver Spring) 2007; 15: 986-93.

5. Weiss JL, Malone FD, Emig D et al. Obesity, obstetric complications and cesarean delivery rate - A populationbased screening study. Am J Obstet Gynecol 2004; 190: 1091-7.

6. Robinson $\mathrm{HE}, \mathrm{O}^{\prime}$ Conell CM, Joseph KS et al. Maternal outcomes in pregnancy complicated by obesity. Obstet Gynecol 2005; 106: 1357-64.

7. Bongain A, Isnard V, Gillet JY. Obesity in obstetrics and gynaecology. Eur J Obstet Gynecol Reprod Biol 1998; 77: 217-28.

8. Watkins MI, Rasmussen SA, Honein MA et al. Maternal obesity and risk for birth defects. Pediatrics 2003; 111: 1152-8.

9. Naimark A, Cherniak R. Compliance of the respiratory system and its components in health and obesity. J Appl Physiol 1960; 15: 377-82.

10. Unterborn J. Pulmonary function testing in obesity, pregnancy, and extremes of body habitus. Clin Chest Med 2001; 22: 759-67.

11. Eng M, Butler J, Bonica JJ. Respiratory function in pregnant obese women. Am J Obstet Gynecol 1975; 123: 241-5.

12. Cullen JH, Formel PF. The respiratory defects in extreme obesity. Am J Med 1962; 32: 525-31.

13. Lee JJ, Larsen RH, Buckley JJ et al. Pulmonary function and its correlation to the degree of obesity in 294 patients. Anesth Rev 1981; 8: 28-32.

14. Vaughan RW, Cork RC, Hollander D. The effect of massive weight loss on arterial oxygenation and pulmonary function tests. Anesthesiology 1981; 54: 325-8.

15. Saravanakumar K, Rao SG, Cooper GM. Obesity and obstetric anesthesia. Anaesthesia 2006; 61: 36-48.

16. Øberg B, Poulsen TD. Obesity: an anaesthetic challenge. Acta Anaesthesiol Scand 1996; 40: 191-200. 
17. Dempsey JA, Reddan W, Rankin J et al. Alveolar arterial gas exchange during muscle work in obesity. J Appl Physiol 1966; 21: 1807-14.

18. Cherniak RM. Respiratory effects of obesity. Can Med Assoc J 1959; 80: 613-6.

19. Lefcourt LA, Rodis JF. Obstructive sleep apnea in pregnancy. Obst Gynecol Surv 1996; 51: 503-6.

20. Parish JM, Somers VK. Obstructive sleep apnea and cardiovascular disease. Mayo Clin Proc 2004; 79: 1036-46.

21. Roush SF, Bell L. Obstructive sleep apnea in pregnancy. J Am Board Fam Pract 2004; 17: 292-4.

22. Chang AB. Physiologic changes of pregnancy. In: Chestnut $\mathrm{DH}$, ed. Obstetric anesthesia: principles and practice, 3rd edn. Philadelphia: Elsevier Mosby, 2004: 15-36.

23. Veille JC, Hanson R. Obesity, pregnancy, and left ventricular functioning during the third trimester. Am J Obstet Gynecol 1994; 171: 980-3.

24. Vasan RS. Cardiac function and obesity. Heart 2003; 89: 1127-9.

25. Tomoda S, Tamura T, Sudo Y et al. Effects of obesity on pregnant women: maternal hemodynamic change. Am J Perinat 1996; 13: 73-8.

26. Shnaider R, Tiberiu E, Szmuk P et al. Combined spinalepidural anesthesia for cesarean section in a patient with peripartum dilated cardiomyopathy. Can J Anesth 2001; 48: 681-3.

27. Tseuda K, Debrand M, Zeok S et al. Obesity supine sudden death syndrome: report of two morbidly obese patients. Anesth Analg 1979; 58: 345-7.

28. Drennick EJ, Fisler JS. Sudden cardiac arrest in morbidly obese surgical patients unexplained after autopsy. Am J Surg 1988; 155: 720-6.

29. Cohen SE. Anesthesia for the morbidly obese pregnant patient. In: Hughes SC, Levinson G, Rosen MA, eds. Shnider and levinson's anesthesia for obstetrics, 4th edn. Philadelphia: Lippincott Williams \&Wilkins, 2002: 545-58.

30. Drenick EJ, Fisler JS. Sudden cardiac arrest in morbidly obese surgical patients unexplained after autopsy. Am J Surg 1988; 155: 720-6.

31. Mendelson CL. The aspiration of stomach contents into the lungs during obstetric anesthesia. Am J Obstet Gynaecol 1945; 52: 191-204.

32. Olsson GL, Hallen B, Hambraeus-Jonzon K. Aspiration during anaesthesia: a computer-aided study of 185358 anaesthestics. Acta Anaesthesiol Scand 1986; 30: 84-92.

33. D'Angelo R, Dewan DD. Obesity. In: Chestnut DH, ed. Obstetric anesthesia: principles and practice, $3 \mathrm{rd}$ edn. Philadelphia: Elsevier Mosby, 2004: 893-903.

34. Roberts RB, Shirley MA. Reducing the risk of acid aspiration during cesarean section. Anest Analg 1974; 53: 859-68.

35. Vaughan RW, Bauer S, Wise L. Volume and $\mathrm{pH}$ of gastric juice in obese patients. Anesthesiology 1975; 43: 686-9.

36. Hess PE, Pratt SD, Lucas TP et al. Predictors of breakthrough pain during labor epidural analgesia. Anesth Analg 2001; 93: 414-8.

37. Melzack R, Kinch R, Dobkin P et al. Severity of labour pain: influence of physical as well as psychologic variables. Can Med Assoc J 1984; 130: 579-84.

38. Ranta P, Jouppila P, Spalding $M$ et al. The effect of maternal obesity on labor and labor pain. Anaesthesia 1995; 50: $322-6$.

39. Hawkins JL, Koonin LM, Palmer SK et al. Anesthesiarelated deaths during obstetric delivery in the United States, 1979-1990. Anesthesiology 1997; 86: 277-84.

40. Hawkins JL. Anesthesia-related maternal mortality. Clin Obstet Gynecol 2003; 46: 679-87.
41. Chadwick HS, Posner K, Caplan RA et al. A comparison of obstetric and non-obstetric anesthesia malpractice claims. Anesthesiology 1991; 74: 242-9.

42. Endler GC, Mariona FG, Solol RJ et al. Anesthesia related mortality in Michigan 1972-1984. Am J Obstet Gynecol 1988; 159: 187-93.

43. Crawforth K. The AANA Foundation closed malpractice claims study: obstetric anesthesia. AANA J 2002; 70: 97-104.

44. The American College of Obstetricians and Gynecologists. Anesthesia for emergency deliveries. ACOG committee opinion no. 104. Washington, DC: American College of Obstetricians and Gynecologists, 1992.

45. Gaiser RR, Mcgonigal ET, Litts P et al. Obstetrician's ability to assess the airway. Obstet Gynecol 1999; 93: 648-52.

46. Jordan H, Perlow MD, Mark A et al. Massive maternal obesity and perioperative cesarean morbidity. Am J Obstet Gynecol 1994; 170: 560-5.

47. Faure E, Moreno R, Thisted R. Incidence of postdural puncture headache in morbidly obese parturients. Reg Anesth 1994; 19: 361-3.

48. Hood DD, Dewan DM, Kashtan K. Anesthesia outcome in the morbidly obese parturient. Anesthesiology 1993; 79: 1210-8.

49. Bahar M, Chanimov M, Cohen ML et al. The lateral recumbent head-down position decreases the incidence of epidural venous puncture during catheter insertion in obese parturients. Can J Anaesth 2004; 51: 577-80.

50. Hamza J, Smida M, Benhamou D et al. Parturient's posture during epidural puncture affects the distance from skin to epidural space. J Clin Anesth 1995; 7: 1-4.

51. Bahk JH, Kim JH, Lee JS et al. Computed tomography study of the lumbar (L3-4) epidural depth and its relationship to physical measurements in young adult men. Reg Anesth Pain Med 1998; 23: 262-5.

52. Watts RW. The influence of obesity on the relationship between body mass index and the distance to the epidural space from the skin. Anaesth Intens Care 1993; 21: 309-10.

53. Wills JS, Bowie R, Bogod DG. A pilot study of patient-led identification of the midline of the lumbar spine. Anaesthesia 2002; 57: 390-4.

54. Maitra AM, Palmer SK, Bachhuber SR et al. Continuous epidural analgesia for cesarean section in a patient with morbid obesity. Anesth Analg 1979; 58: 348-9.

55. Grau T, Leipold RW, Horter J et al. The lumbar epidural space in pregnancy: visualization by ultrasonography. $\mathrm{Br} \mathrm{J}$ Anaesth 2001; 86: 798-804.

56. Grau T, Leipold RW, Conradi R et al. Paramedian access to the epidural space: the optimum window for ultrasound imaging. J Clin Anesth 2001; 13: 213-7.

57. Wallace DH, Currie JM, Gilstrap LC et al. Indirect sonographic guidance for epidural anesthesia in obese pregnant patients. Reg Anesth 1992; 17: 233-6.

58. Faheem M, Sarwar N. Sliding of the skin over subcutaneous tissue is another important factor in epidural catheter migration. Can J Anesth 2002; 49: 634.

59. Iwama H, Katayama T. Back skin movement also causes 'walking' epidural catheter. J Clin Anesth 1999; 11: 140-1.

60. Hamilton CL, Riley ET, Cohen SE. Changes in the position of epidural catheters associated with patient movement. Anesthesiology 1997; 86: 778-84.

61. Poulton B, Young P. A novel method for epidural catheter fixation. Anaesthesia 2000; 55: 1141.

62. van de Velde M, Teunkens A, Hanssens M et al. Post dural puncture headache following combined spinal epidural or epidural anesthesia in obstetric patients. Anaesth Intensive Care 2001; 29: 595-9. 
63. Pan PH, Bogard TD, Owen MD. Incidence and characteristics of failures in obstetric neuraxial analgesia and anesthesia: a retrospective analysis of 19,259 deliveries. Int J Obstet Anesth 2004; 13: 227-33.

64. Norris MC. Are combined spinal-epidural catheters reliable? Int J Obstet Anesth 2000; 9: 3-6.

65. Eappen S, Blinn A, Segal S. Incidence of epidural catheter replacement in parturients: a retrospective chart review. Int J Obstet Anesth 1998; 7: 220-5.

66. Riley ET, Papasin J. Epidural catheter function during labor predicts anesthetic efficacy for subsequent cesarean delivery. Int J Obstet Anesth 2002; 11: 81-4.

67. Hogan QH, Prost R, Kulier A et al. Magnetic resonance imaging of cerebrospinal fluid volume and the influence of body habitus and abdominal pressure. Anesthesiology 1996; 84: 1341-9.

68. Panni MK, Columb MO. Obese parturients have lower epidural local anaesthetic requirements for analgesia in labour. Br J Anaesth 2006; 96: 106-10.

69. Bromage PR. Accidental dural puncture. In: Bromage PR, ed. Epidural Analgesia. Philadelphia, WB: Saunders, 1978: 206-12.

70. Denny N, Masters R, Pearson D et al. Postdural puncture headache after continuous spinal anesthesia. Anesth Analg 1987; 66: 791-4.

71. Norris MC, Leighton BL. Continuous spinal anesthesia after unintentional dural puncture in parturients. Reg Anesth 1990; 15: 285-7.

72. Cohen S, Amar D, Pantuck EJ et al. Decreased incidence of headache after accidental dural puncture in caesarean delivery patients receiving continuous postoperative intrathecal analgesia. Acta Anaesthesiol Scand 1994; 38: 716-8.

73. Norris MC, Leighton BL, DeSimone CA. Needle bevel direction and headache after inadvertent dural puncture. Anesthesiology 1989; 70: 729-31.

74. Perlow JH, Morgan MA. Massive maternal obesity and perioperative cesarean morbidity. Am J Obstet Gynecol 1994; 170: $560-4$.

75. Gross TL. Operative considerations in the obese pregnant patient. Clin Perinatol 1983; 10: 411-21.

76. American Society of Anesthesiologists Task Force on Perioperative Management of Patients with Obstructive Sleep Apnea. Practice Guidelines for the Perioperative Management of Patients with Obstructive Sleep Apnea. Anesthesiology 2006; 104: 1081-93.

77. Charbonneau M, Falcone T, Cosio MG et al. Obstructive sleep apnea during pregnancy. Am Rev Respir Dis 1991; 144: 461-3.

78. Lewi DF, Chesson AL, Edwards MS et al. Obstructive sleep apnea during pregnancy resulting in pulmonary hypertension. South. Med J 1998; 91: 761-2.

79. Kowall J, Clark G, Nino-Murcia G et al. Precipitation of obstructive sleep apnea during pregnancy. Obstet Gynecol 1989; 74: 453-5.

80. Kernstein MD, McSwain NE, O'Conell RC et al. Obesity: is it a risk factor in thrombophlebitis? South Med J 1987; 80: $1236-8$.

81. Larsen TB, Sorensen HT, Gislum M et al. Maternal smoking, obesity, and risk of venous thromboembolism during pregnancy and the puerperium: a population-based nested case-control study. Thromb Res 2007; 120: 505-9.

82. Rocha AT, de Vasconcellos AG, da Luz Neto ER et al. Risk of venous thromboembolism and efficacy of thromboprophylaxis in hospitalized obese medical patients and in obese patients undergoing bariatric surgery. Obes Surg 2006; 16: 1645-55.
83. Hodgkinson R, Husain FJ. Obesity and the cephalad spread of analgesia following epidural administration of bupivacaine for cesarean section. Anesth Analg 1980; 59: 89-92.

84. Hackney JD, Crane MG, Collier CC et al. Syndrome of extreme obesity and hypoventilation: studies of etiology. Ann Int Med 1960; 51: 541-52.

85. Greene NM. Distribution of local anesthetic solutions within the subarachnoid space. Anesth Analg 1985; 64: 715-30.

86. Kuczkowski KM, Benumof JL. Repeat cesarean section in a morbidly obese parturient: a new anesthetic option. Acta Anaesthesiol Scand 2002; 46: 753-4.

87. Rawal N, Holmstrom B, Crowhurst JA et al. The combined spinal-epidural technique. Anesth Clin North Am 2000; 18: 267-95.

88. Goy RW-L, Sia AT-H. Sensorimotor anesthesia and hypotension after subarachnoid block: combined spinal-epidural versus single-shot spinal technique. Anesth Analg 2004; 98: 491-6.

89. Rawal N, Schollin J, Wesström G. Epidural versus combined spinal epidural block for Caesarean section. Acta Anaesthesiol Scand 1988; 32: 61-6.

90. O'Sullivan GM, Bullingham RES. The assessment of gastric acidity and antacid effect in pregnant women by a noninvasive radiotelemetry technique. $\mathrm{Br} J$ Obstet Gynaecol 1984; 91: 973-8.

91. O'Sullivan GM, Guyton TS. Aspiration: risk, prophylaxis, and treatment. In: Chestnut DH, ed. Obstetric anesthesia. Principles and practice, 3rd edn. Philadelphia: Elsevier Mosby, 2004:523-34.

92. Orr DA, Bill KM, Gillon KR et al. Effects of omeprazole, with and without metoclopramide, in elective obstetric anaesthesia. Anaesthesia 1993; 48: 114-9.

93. Stuart JC, Kan AF, Rowbottom SJ et al. Acid aspiration prophylaxis for emergency caesarean section. Anaesthesia 1996; 51: 415-21.

94. Rocke DA, Murray WB, Route CC et al. Relative risk analysis of factors associated with difficult intubation in obestric anesthesia. Anesthesiology 1992; 77: 67-73.

95. Brodsky JB, Lemmens HJM, Brock-Utne JG et al. Morbid obesity and tracheal intubation. Anesth Analg 2002; 94: 732-6.

96. Hamilton W, Eastwood D. A study of denitrogenation with some inhalation anesthetic system. Anesthesiology 1955; 16: 861-7.

97. Gold MI, Durate I, Muravchick S. Arterial oxygenation in conscious patients after $5 \mathrm{~min}$ and after $30 \mathrm{~s}$ of oxygen breathing. Anesth Analg 1981; 60: 313-5.

98. Norris MC, Dewan DM. Preoxygenation for cesarean section: a comparison of two techniques. Anesthesiology 1985; 62: 827-9.

99. Baraka AS, Taha SK, Aouad MT et al. Preoxygenation comparison of maximal breathing and tidal volume breathing techniques. Anesthesiology 1999; 91: 612-6.

100. Chiron B, Laffon M, Ferrandiere M et al. Standard preoxygenation technique versus two rapid techniques in pregnant patients. Int J Obstet Anesth 2004; 13: 11-4.

101. Dixon BJ, Dixon JB, Carden JR et al. Preoxygenation is more effective in the 25 degrees head-up position than in the supine position in severely obese patients: a randomized controlled study. Anesthesiology 2005; 102: 1110-5.

102. Altermatt FR, Muñoz HR, Delfino AE et al. Pre-oxygenation in the obese patient: effects of position on tolerance to apnoea. Br J Anaesth 2005; 95: 706-9. 
103. Brain AIJ, Verghese C, Strube PJ. The LMA 'ProSeal' - a laryngeal mask with an oesophageal vent. $\mathrm{Br} J$ Anaesth 2000; 84: 650-4.

104. Collins JS, Lemmens HJ, Brodsky JB et al. Laryngoscopy and morbid obesity: a comparison of the 'sniff' and 'ramped' positions. Obes Surg 2004; 14: 1171-5.

105. Ogunnaike BO, Whitten CW. Anesthesia and obesity. In: Barash PG, Cullen BF, Stoelting RK, eds. Clinical anesthesia, 5th edn. Philadelphia: Lippincott Williams \& Wilkins, 2006: 1040-52.

106. Viby-Mogensen J. Correlation of succinylcholine duration of action with plasma cholinesterase activity in subjects with the genotypically normal enzyme. Anesthesiology 1980; 53: 517-20.

107. Bentley JB, Borel JD, Vaughan RW et al. Weight, pseudocholinesterase activity and weight requirement. Anesthesiology 1982; 57: 48-9.

108. Abboud TK, Zhu J, Richardson M et al. Desflurane: a new volatile anesthetic for cesarean section. Maternal and neonatal effects. Acta Anaesthesiol Scand 1995; 39: 723-6.

109. Strum EM, Szenohradszki J, Kaufman WA et al. Emergence and recovery characteristics of desflurane versus sevoflurane in morbidly obese adult surgical patients: a prospective, randomized study. Anesth Analg 2004; 99: 1848-53.

110. Benumof JL. Obstructive sleep apnea in the adult obese patient: implications for airway management. Anesthesiol Clin N Am 2002; 20: 789-811.

111. Naef RW III, Chauhan SP, Chevalier SP et al. Prediction of hemorrhage at cesarean delivery. Obstet Gynecol 1994; 83: 923-5.

112. Myles TD, Gooch J, Santolaya J. Obesity as an independent risk factor for infectious morbidity in patients who undergo cesarean delivery. Obstet Gynecol 2002; 100: 959-64.

113. Tran TS, Jamulitrat S, Chongsuvivatwong V et al. Risk factors for postcesarean surgical site infection. Obstet Gynecol 2000; 95: 367-71.

114. ACOG Committee Opinion \# 315. Obesity in pregnancy. Obstet Gynecol 2005; 106: 671-5.
115. Eichenberger AS, Proietti S, Wicky S et al. Morbid obesity and postoperative pulmonary atelectasis: an underestimated problem. Anesth Analg 2002; 95: 1788-92.

116. von Ungern-Sternberg BS, Regli A, Bucher E et al. Impact of spinal anaesthesia and obesity on maternal respiratory function during elective Caesarean section. Anaesthesia 2004; 59: 743-9.

117. Vaughan RW, Bauer S, Wise L. Effect of position (semirecumbent versus supine) on postoperative oxygenation in markedly obese subjects. Anesth Analg 1976; 55: 37-41.

118. Lim Y, Jha S, Sia AT et al. Morphine for post-caesarean section analgesia: intrathecal, epidural or intravenous? Singapore Med J 2005; 46: 392-6.

119. Ballantyne JC, Carr DB, deFerranti $S$ et al. The Comparative effetcs of postoperative analgesic therapies on pulmonary outcome: cumulative meta-analysis of randomized,controlled trials. Anesth Analg 1998; 86: 598-612.

120. Levin A, Klein SL, Brolin RE et al. Patient-controlled analgesia for morbidly obese patients: an effective modality if used correctly. Anesthesiology 1992; 76: 857-8.

121. Michota F, Merli G. Anticoagulation in special patient populations: are special dosing considerations required? Clev Clin J Med 2005; 72 (Suppl. 1): S37-42.

122. Horlocker TT, Wedel DJ, Benzon $\mathrm{H}$ et al. Regional anesthesia in the anticoagulated patient: defining the risks (the second ASRA consensus conference on neuraxial anesthesia and anticoagulation). Reg Anest Pain Med 2003; 28: 172-97.

Address:

David J Birnbach

Department of Anesthesiology

Perioperative Medicine and Pain Management

Jackson Memorial Hospital

1611 NW 12th Avenue, c-300

Miami, FL 33136

USA

e-mail: dbirnbach@med.miami.edu 